\title{
Prevotella maculosa sp. nov., isolated from the human oral cavity
}

\author{
Correspondence \\ William G. Wade \\ william.wade@kcl.ac.uk
}

\author{
Julia Downes, ${ }^{1}$ lain C. Sutcliffe, ${ }^{2}$ Veronica Booth ${ }^{1}$ and William G. Wade \\ ${ }^{1}$ King's College London Dental Institute at Guy's, King's College and St Thomas' Hospitals, \\ Infection Research Group, London SE1 9RT, UK \\ ${ }^{2}$ Division of Biomedical Sciences, School of Applied Sciences, Northumbria University, \\ Newcastle upon Tyne NE1 8ST, UK
}

Prevotella species are part of the normal human oral microbiota and are also frequently isolated from oral infections such as periodontitis, dental caries and abscesses (Dymock et al., 1996; Paster et al., 2001; Nadkarni et al., 2004). However, many isolates encountered in clinical samples cannot be assigned to species with validly published names. In this study, a group of three such strains were characterized by a variety of phenotypic and genotypic methods.

Strain $\mathrm{W} 1609^{\mathrm{T}}$ was isolated from the exudate from pericoronitis associated with a third molar, W2051 from an infection associated with a dental implant and W6974 from subgingival plaque in a periodontally healthy subject. Prevotella oris ATCC $33573^{\mathrm{T}}$ was obtained from the ATCC and Prevotella salivae DSM $15606^{\mathrm{T}}$ from the DSMZ. Prevotella oris W1864 and Prevotella salivae W1640 were isolated from exudates from pericoronitis in third molars.

Strains were grown at $37{ }^{\circ} \mathrm{C}$ on fastidious anaerobe agar (FAA; LabM) supplemented with $5 \%$ horse blood under anaerobic conditions $\left(80 \% \mathrm{~N}_{2}, 10 \% \mathrm{H}_{2}, 10 \% \mathrm{CO}_{2}\right)$ in an anaerobic workstation (Don Whitley Scientific). Colonial morphologies were determined after 3 days incubation using a dissecting microscope. Cellular morphology was recorded after Gram-staining of smears prepared from 2day FAA cultures. Hanging-drop preparations of $18 \mathrm{~h}$

Abbreviation: FAME, fatty acid methyl ester.

The GenBank/EMBL/DDBJ accession numbers for the two 16S rRNA gene sequences obtained from Prevotella maculosa $\mathrm{W}_{1609^{\top}}$ are EF534314 and EF534315.

An extended phylogenetic tree, a summary of the characteristics of the novel species and a comparison of FAME profiles are available as supplementary material with the online version of this paper. cultures of peptone/yeast extract/glucose (PYG) broth were examined under phase-contrast microscopy for cellular motility.

Biochemical tests were performed using standard methods (Holdeman et al., 1977; Jousimies-Somer et al., 2002). Fermentation tests were performed using prereduced, anaerobically sterilized (PRAS) sugars prepared in an anaerobic workstation (Holdeman et al., 1977). Susceptibility to special-potency antibiotic discs separately containing vancomycin $(5 \mu \mathrm{g})$, kanamycin $(1 \mathrm{mg})$ and colistin $(10 \mu \mathrm{g})$ was determined on FAA (Jousimies-Somer et al., 2002). Bacterial strains were grown in peptone/yeast extract (PY) broth with and without glucose and shortchain volatile and non-volatile fatty acids were extracted by standard methods and analysed by gas chromatography (Holdeman et al., 1977). Enzyme profiles were generated in duplicate with the Rapid ID 32A anaerobe identification kit (bioMérieux), according to the manufacturer's instructions, using bacteria harvested from Columbia agar plates (LabM) supplemented with $5 \%$ horse blood.

Cellular fatty acid composition was determined as described previously (Sutcliffe, 2000; Downes et al., 2005). Fatty acid methyl esters (FAMEs) were identified by comparison with authentic FAME standards (Sigma). The G+C content of the DNA of strains $\mathrm{W} 1609^{\mathrm{T}}$ and W6974 was determined by an HPLC method as described previously (Wade et al., 1999). A thermal renaturation method (Huß et al., 1983) was used to estimate the DNADNA relatedness between strain $\mathrm{W} 1609^{\mathrm{T}}$ and the type strains of $P$. oris and P. salivae.

The 16S rRNA genes of the strains were sequenced as described previously (Downes et al., 2005). Sequences were 
connected using the BioEdit programme (Hall, 2004) and provisionally identified by BLAST interrogation of the GenBank database (Altschul et al., 1990). Phylogenetic analysis was performed using MEGA version 3.1 (Kumar et al., 2004). Phylogenetic trees were constructed by the neighbour-joining method from distance matrices prepared using the Jukes-Cantor correction.

Individual PCR-amplified 16S rRNA genes from strain $\mathrm{W} 1609^{\mathrm{T}}$ were isolated by cloning using the TOPO TA cloning kit and TOP10 chemically competent cells (Invitrogen). Ten cloned genes were partially sequenced with primer 519R.

The results of the phenotypic tests are tabulated in Supplementary Table S1, available in IJSEM Online. The strains were obligately anaerobic, non-motile, non-pigmenting, Gram-negative bacilli, $0.7 \mu \mathrm{m}$ wide by $1-3 \mu \mathrm{m}$ long, with occasional cells up to $6 \mu \mathrm{m}$ long. After 3 days incubation on FAA medium, colonies were $1.4-1.8 \mathrm{~mm}$ in diameter, circular, entire, convex, grey, shiny and opaque with a slightly mottled internal appearance when viewed under a plate microscope. Strains were resistant to specialpotency discs containing vancomycin, colistin and kanamycin. Growth of all strains in PY broth produced a moderately turbid suspension ( 2 to $3+$ on a scale of 0 to $4+)$. Growth was enhanced by the addition of $1 \%$ fermentable carbohydrates (3 to $4+$ ). Strains were saccharolytic (see species description for sugar reactions) and major amounts of acetic and succinic acids were produced as end products of glucose metabolism. Aesculin was hydrolysed but other biochemical tests were negative (see species description). The $\mathrm{G}+\mathrm{C}$ content of the DNA of strains $\mathrm{W} 1609^{\mathrm{T}}$ and $\mathrm{W} 6974$ was $48 \mathrm{~mol} \%$.

The strains gave positive reactions in the Rapid ID 32A panel for $\alpha$-galactosidase, $\beta$-galactosidase, $\alpha$-glucosidase, $\beta$ glucosidase, $\alpha$-arabinosidase, $N$-acetyl- $\beta$-glucosaminidase, mannose fermentation, raffinose fermentation, alkaline phosphatase, leucyl glycine arylamidase and alanine arylamidase, while $\beta$-glucuronidase production was weak and variable. Negative reactions were obtained for the remaining 17 tests, resulting in a profile of $45^{3} / 77440200$. The enzyme profiles for the two strains of $P$. oris were 4537440220 and 4537440222 for the two strains of $P$. salivae. $P$. salivae and $P$. oris strains gave a positive reaction for $\alpha$-fucosidase while the strains of the novel group were negative; for glutamyl glutamic acid arylamidase, $P$. salivae was positive and $P$. oris and the novel group were negative; $\beta$-glucuronidase was variable for the novel group but negative for $P$. oris and P. salivae.

Assembly of the 16S rRNA gene sequences for strain $\mathrm{W} 1609^{\mathrm{T}}$ revealed a number of ambiguous bases in helix 6 in variable region 1 . Sequencing of individual amplified genes isolated by cloning revealed two versions of the stem section of helix 6, which differed by 12 bases (Fig. 1). The two versions were designated $\mathrm{A}$ and $\mathrm{B}$ and version $\mathrm{A}$ was used for the subsequent sequence identity comparisons. Heterogeneity within multiple rRNA operons within
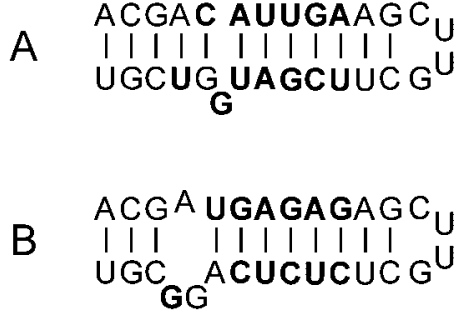

Fig. 1. Sequence variation in helix 6 between variants $A$ and $B$ of the $16 \mathrm{~S}$ rRNA gene of strain $\mathrm{W} 1609^{\top}$.

genomes is well-known. Among 83 bacterial genomes with multiple rRNA operons, $62 \%$ were found to exhibit $16 \mathrm{~S}$ rRNA gene intragenomic heterogeneity (Case et al., 2007). However, this heterogeneity is rarely noted in species descriptions; it was so marked for strain $\mathrm{W} 1609^{\mathrm{T}}$ that the two versions of the gene have been submitted to GenBank.

Phylogenetic analysis of the two 16S rRNA gene sequences for $\mathrm{W} 1609^{\mathrm{T}}$ revealed this organism to belong to the genus Prevotella (Fig. 2; see Supplementary Fig. S1 for a fuller phylogenetic tree). The $16 \mathrm{~S}$ rRNA gene was also sequenced from strains W2051 and W6974 and showed 98.3\% sequence identity or greater to strain $\mathrm{W} 1609^{\mathrm{T}}$ sequence variant A (W1609A) over 1454 unambiguously aligned bases. The most closely related sequences in GenBank were from oral clones Prevotella AA020 (GenBank accession no. AY005057) and Prevotella AA016 (AY005058), with sequence identities to W1609A of 98.8 and $98.6 \%$ respectively. The most closely related species to W1609A with validly published names were $P$. oris $(94.0 \%$ sequence identity to the type strain) and P. salivae (94.1\%).

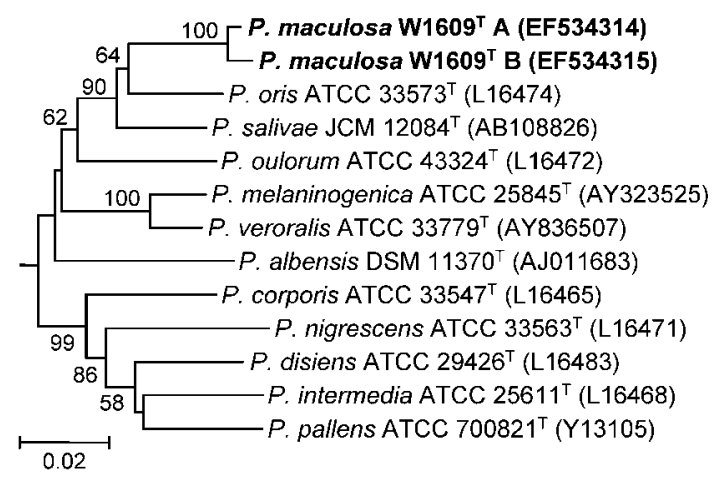

Fig. 2. Phylogenetic tree based on $16 \mathrm{~S}$ rRNA gene sequence comparisons over 1411 aligned bases showing the relationship between Prevotella maculosa sp. nov. $\mathrm{W} 1609^{\top}$ and related species. The tree was constructed using the neighbour-joining method following distance analysis of aligned sequences. Numbers represent bootstrap values for each branch based on data for 100 trees. Accession numbers for 16S rRNA gene sequences are given for each strain. Bar, 0.02 substitutions per nucleotide site. 
Table 1. Phenotypic characteristics that differentiate strains $\mathrm{W} 1609^{\top}$, W2051 and W6974 (Prevotella maculosa sp. nov.) from other Prevotella species

Species: 1, P. buccae; 2, P. dentalis; 3, P. oris; 4, P. salivae; 5, P. maculosa sp. nov.; 6, P. bergensis; 7, P. oralis; 8, P. baroniae; 9, P. buccalis; 10, P. loescheii; 11, P. veroralis; 12, P. multiformis; 13, P. denticola; 14, P. melaninogenica; 15, P. shahii; 16, P. oulorum; 17, P. enoeca; 18, P. bivia; 19, P. tannerae; 20, P. intermedia; 21, P. nigrescens; 22, P. corporis; 23, P. marshii; 24, P. pallens; 25, P. disiens. W, Weak; v, variable; NA, no data available. Data for reference species (with the exception of $\alpha$-fucosidase and glutamyl glutamic acid arylamidase activities, which were determined in this study from the reference strains mentioned in the text) were taken from the original descriptions.

\begin{tabular}{|c|c|c|c|c|c|c|c|c|c|c|c|c|c|c|c|c|c|c|c|c|c|c|c|c|c|}
\hline Characteristic & 1 & 2 & 3 & 4 & 5 & 6 & 7 & 8 & 9 & 10 & 11 & 12 & 13 & 14 & 15 & 16 & 17 & 18 & 19 & 20 & 21 & 22 & 23 & 24 & 25 \\
\hline Pigment $^{*}$ & - & - & - & - & - & - & - & - & - & + & - & - & + & + & + & - & - & - & + & + & + & + & - & + & - \\
\hline \multicolumn{26}{|l|}{ Fermentation of: } \\
\hline Arabinose & + & + & + & + & + & + & - & - & - & - & - & - & - & - & - & - & - & - & - & - & - & - & - & - & - \\
\hline Cellobiose & + & + & + & + & + & + & + & + & + & + & + & + & - & - & - & - & - & - & - & - & - & - & - & - & - \\
\hline Lactose & + & + & + & + & + & + & + & + & + & + & + & + & + & + & + & + & + & + & V & - & - & - & - & - & - \\
\hline Mannose & + & + & + & + & + & + & + & + & + & + & + & + & + & + & + & + & $\mathrm{V}$ & + & V & V & + & + & v & - & - \\
\hline Raffinose & + & + & + & + & + & - & + & + & + & + & + & + & + & + & + & + & - & - & V & V & + & - & - & + & - \\
\hline Salicin & + & - & + & + & + & + & + & + & - & - & - & - & - & - & - & - & - & - & - & - & - & - & - & - & - \\
\hline Sucrose & + & w & + & + & + & - & + & + & + & + & + & + & + & + & + & + & - & - & V & + & + & - & - & + & - \\
\hline Indole production & - & - & - & - & - & - & - & - & - & - & - & - & - & - & - & - & - & - & - & + & + & - & - & + & - \\
\hline Aesculin hydrolysis & + & + & + & + & + & + & + & + & + & + & + & - & + & $\mathrm{v}$ & - & + & $\mathrm{V}$ & - & - & - & - & - & - & - & - \\
\hline Gelatin hydrolysis & + & - & $\mathrm{V}$ & - & - & - & $\mathrm{V}$ & $\mathrm{w}$ & - & + & $\mathrm{V}$ & + & + & + & + & - & + & + & + & + & + & + & + & + & + \\
\hline$\alpha$-Fucosidase & NA & & + & + & - & NA & $\mathrm{NA}$ & $\mathrm{NA}$ & $\mathrm{NA}$ & NA & NA & NA & NA & $\mathrm{NA}$ & $\mathrm{NA}$ & $\mathrm{NA}$ & $\mathrm{NA}$ & $\mathrm{NA}$ & $\mathrm{NA}$ & NA & NA & NA & NA & $\mathrm{NA}$ & NA \\
\hline Glutamyl glutamic acid arylamidase & $\mathrm{NA}$ & $\mathrm{NA}$ & - & + & - & NA & $\mathrm{NA}$ & $\mathrm{NA}$ & NA & NA & $\mathrm{NA}$ & NA & NA & NA & NA & $\mathrm{NA}$ & NA & NA & $\mathrm{NA}$ & $\mathrm{NA}$ & $\mathrm{NA}$ & NA & NA & NA & NA \\
\hline
\end{tabular}

${ }^{\star}$ Pigmentation on blood agar may take up to 14 days and varies from tan through brown to black depending on the species.

Cellular FAME results for the three strains are shown in Supplementary Table S2. The FAME profiles were consistent with previous analyses of Prevotella species (Supplementary Table S2), with a relatively high proportion of palmitic acid noted. These data further confirm the need for a comprehensive, standardized survey of fatty acid composition in Prevotella and closely related genera.

DNA-DNA relatedness between strain $\mathrm{W} 1609^{\mathrm{T}}$ and the type strains $P$. oris ATCC $33573^{\mathrm{T}}$ and $P$. salivae DSM $15606^{\mathrm{T}}$ was determined to be 6 and $12 \%$, respectively.

The strains studied here constitute a homogeneous group and are clearly distinct from any species with validly published names. We therefore propose the name Prevotella maculosa sp. nov. for this group. Phenotypic characteristics that distinguish $P$. maculosa from the other Prevotella species are shown in Table 1. Conventional biochemical tests, commonly used to differentiate members of the genus Prevotella, were unable to distinguish $P$. maculosa from P. oris and P. salivae. However, tests for $\alpha$ fucosidase and glutamyl glutamic acid arylamidase, included in the Rapid ID 32A kit, could differentiate the species, as described above. However, when additional strains become available, these should be tested to confirm the reliability of species differentiation based on these tests.

\section{Description of Prevotella maculosa sp. nov.}

Prevotella maculosa (ma.cu.lo'sa. L. fem. adj. maculosa speckled, referring to the internal appearance of colonies of the organism growing on agar media).
The description is based on three strains isolated from the human mouth. Cells are obligately anaerobic, non-motile, non-pigmenting, Gram-negative bacilli, $0.7 \mu \mathrm{m}$ wide by $1-$ $3 \mu \mathrm{m}$ long, with occasional cells up to $6 \mu \mathrm{m}$ long. After 3 days incubation on FAA medium, colonies are 1.4$1.8 \mathrm{~mm}$ in diameter, circular, entire, convex, opaque, shiny and grey, with a slightly mottled internal appearance. Growth in broth media produces a moderate turbidity that is enhanced by the addition of fermentable carbohydrates. Cells are saccharolytic and ferment arabinose, cellobiose, fructose, glucose, lactose, maltose, mannose, melibiose, raffinose, rhamnose, salicin, sucrose and xylose; mannitol, melezitose and sorbitol are not fermented. Major amounts of acetic and succinic acids are produced as end products of metabolism in PYG broth. The non-hydroxylated fatty acid profile is predominantly anteiso- $\mathrm{C}_{15: 0}$ and $\mathrm{C}_{16: 0}$, with lesser amounts of iso- $\mathrm{C}_{15: 0}$ and iso- $\mathrm{C}_{17: 0}$. Aesculin is hydrolysed; arginine, gelatin and urea are not hydrolysed. Indole and catalase are not produced and nitrate is not reduced. There is no growth in $20 \%$ bile. The $\mathrm{G}+\mathrm{C}$ content of the DNA of the type strain is $48 \mathrm{~mol} \%$.

The type strain, $\mathrm{W} 1609^{\mathrm{T}} \quad\left(=\mathrm{DSM} 19339^{\mathrm{T}}=\mathrm{CCUG}\right.$ $\left.54766^{\mathrm{T}}\right)$, and strains $\mathrm{W} 2051$ and W6974 were isolated from the human oral cavity.

\section{References}

Altschul, S. F., Gish, W., Miller, W., Myers, E. W. \& Lipman, D. J. (1990). Basic local alignment search tool. J Mol Biol 215, 403-410. 
Case, R. J., Boucher, Y., Dahllöf, I., Holmström, C., Doolittle, W. F. \& Kjelleberg, S. (2007). Use of $16 \mathrm{~S}$ rRNA and $r p o B$ genes as molecular markers for microbial ecology studies. Appl Environ Microbiol 73, 278-288.

Downes, J., Sutcliffe, I. C., Tanner, A. C. R. \& Wade, W. G. (2005). Prevotella marshii sp. nov. and Prevotella baroniae sp. nov. isolated from the human oral cavity. Int J Syst Evol Microbiol 55, 1551-1555.

Dymock, D., Weightman, A. J., Scully, C. \& Wade, W. G. (1996). Molecular analysis of microflora associated with dentoalveolar abscesses. J Clin Microbiol 34, 537-542.

Hall, T. (2004). BioEdit. Biological sequence alignment editor for Win95/98/NT/2K/XP. http://www.mbio.ncsu.edu/BioEdit/bioedit.html

Holdeman, L. V. H., Cato, E. P. \& Moore, W. E. C. (1977). Anaerobe Laboratory Manual, 4th edn. Blacksburg, VA: Virginia Polytechnic Institute and State University.

Huß, V. A. R., Festl, H. \& Schleifer, K. H. (1983). Studies on the spectrophotometric determination of DNA hybridization from renaturation rates. Syst Appl Microbiol 4, 184-192.

Jousimies-Somer, H., Summanen, P., Citron, D. M., Baron, E. J., Wexler, H. M. \& Finegold, S. M. (2002). Wadsworth Anaerobic Bacteriology Manual, 6th edn. Belmont, CA: Star Publishing.
Kumar, S., Tamura, K. \& Nei, M. (2004). MEGA3: integrated software for molecular evolutionary genetics analysis and sequence alignment. Brief Bioinform 5, 150-163.

Nadkarni, M. A., Caldon, C. E., Chhour, K. L., Fisher, I. P., Martin, F. E., Jacques, N. A. \& Hunter, N. (2004). Carious dentine provides a habitat for a complex array of novel Prevotella-like bacteria. J Clin Microbiol 42, 5238-5244.

Paster, B. J., Boches, S. K., Galvin, J. L., Ericson, R. E., Lau, C. N., Levanos, V. A., Sahasrabudhe, A. \& Dewhirst, F. E. (2001). Bacterial diversity in human subgingival plaque. J Bacteriol 183, 3770-3783.

Sutcliffe, I. C. (2000). Characterisation of a lipomannan lipoglycan from the mycolic acid containing actinomycete Dietzia maris. Antonie van Leeuwenhoek 78, 195-201.

Wade, W. G., Downes, J., Dymock, D., Hiom, S. J., Weightman, A. J., Dewhirst, F. E., Paster, B. J., Tzellas, N. \& Coleman, B. (1999). The family Coriobacteriaceae: reclassification of Eubacterium exiguum (Poco et al. 1996) and Peptostreptococcus heliotrinreducens (Lanigan 1976) as Slackia exigua gen. nov., comb. nov. and Slackia heliotrinireducens gen. nov., comb. nov., and Eubacterium lentum (Prévot 1938) as Eggerthella lenta gen. nov., comb. nov. Int J Syst Bacteriol 49, 595-600. 